\title{
Re-Inventing the Microscope: The Canadian Light Source (CLS)
}

magine a microscope with the technological equipment and space the size of a football field. That's the Canadian Light Source (CLS) - Canada's national facility for synchrotron light research, which officially opened its doors at the University of Saskatchewan on October 22, 2004 (Canadian Light Source Inc. 2004a).

Launched in 1999, the CLS was a $\$ 174$ million capital project. It was praised by then Natural Resources Minister Ralph Goodale as a strategic move that would enable Canada to "take a quantum leap forward" in the fields of innovation and scientific knowledge (Canadian Light Source Inc. 2004a).

Funding for the project came from a variety of federal, provincial and municipal sources. For its part, the Canadian Institutes of Health Research (CIHR) has provided over \$10 million for operational procedures of the CLS, and will continue to contribute to the ongoing operating costs of the CLS.

\section{What Does This Invention Do?}

The CLS will provide both savings and discovery for health researchers.

Prior to the launch of this synchrotron, Canada was the only G8 country that did not have one. As a result, researchers spent millions to travel around the world and buy time using the 40 other synchrotrons in existence (in places as far away as Japan) (Canadian Light Source Inc. 2004b). With the development of the CLS, researchers, funded by CIHR, can access a Canadian instrument without having to pay user fees.

It is estimated that the CLS will attract about $\$ 35$ million annually to Canada in commercial research and development spending (Canadian Light Source Inc. 2004b), which will increase job opportunities on all technological fronts in order to keep the CLS fully functional.

As Canada's largest and most powerful microscope, this invention was about 30 years in the making. Researchers were clamouring for its development in the mid-1970s, because of its powers of scientific perception.

The CLS accelerates a stream of electrons close to the speed of light. The electrons travel around a ring-shaped (stainless steel) vacuum chamber that is about as thick as a man's wrist.

Electromagnets built around this stainless steel pipe deflect the electrons to keep them moving around the ring. As the high-speed electrons are deflected, they emit radiation across a continuous spectrum of light from infrared to X-rays.
This brilliant radiation, which is about a billion times brighter than sunlight, is directed into various "beamlines" (or experimental stations), where researchers can select the wavelengths they need for their studies. Two existing beamlines are particularly relevant to health research. The protein crystallography $(\mathrm{PX})$ beamline will help determine the atomic structures of biological macromolecules, and the infrared beamline will be used for high-resolution tissue imaging (Canadian Light Source Inc. 2004c).

\section{What Does This Mean for the Field of Life Sciences?}

The medical and biological benefits of the CLS are enormous. Protein crystallography, for example, has advanced a great deal over the past few decades, thanks largely to the intense and focused light available from synchrotron radiation, which allows very small crystals to be used in working out the atomic structure of proteins. Knowing the atomic structure of a protein molecule allows for the better design of small molecules that will interact with the active sites on the proteins. For example, recent antiviral drugs against AIDS were developed

using knowledge of detailed protein-drug interactions (Canadian Light Source 2004c).

The infrared beamline provided by the synchrotron will be useful to medical sciences because it can offer measured insights into a variety of diseases. Infrared microspectroscopy allows chemical information to be obtained from tissues at higher resolution, and more quickly than with other approaches. 
Canadian researchers who have already used synchrotrons internationally have been able to study problematic heart tissue in hamsters, as well as brain tissue damaged by Alzheimer's disease. As if this weren't enough, preliminary research published in the journal Nature suggests that synchrotrons will enable health researchers to determine whether a woman will develop breast cancer based on a single strand of her own hair (Canadian Light Source 2004b).

In the second stage of CLS commissioning, a third beamline relevant to health research will be added: the biomedical imaging and therapy beamline. Novel imaging techniques being developed by the CLS team reveal previously invisible details in soft tissue, such as breast tumour fibres and deteriorating cartilage between arthritic bones.

The CLS will also provide cross-disciplinary education for graduate students, as it is expected that pharmaceutical companies will establish protein crystallography laboratories in Canada to study the three-dimensional structure of proteins.

Researchers in Saskatchewan expect that about 2,000 international colleagues will visit the CLS facility every year (Western Economic Diversification Canada 2004). As it stands, over 400 scientists from diverse fields are already involved with the CLS - and that number is expected to grow substantially (Western Economic Diversification Canada 2004). In fact, scientists from over 18 Canadian universities will benefit from the facility (CBC News 2004).

\section{Concluding Thoughts}

There is no doubt about it: the development of the CLS is good news for health research. Its development will offer researchers from all backgrounds the opportunity to converge, break down independent silos of training and work together towards creating new knowledge that will improve healthcare for all Canadians.

The CLS will provide new insights into disease processes, discoveries leading to improved disease prevention and diagnosis and innovations in therapy.

\section{References}

Canadian Light Source Inc. 2004a. News Release Communique (October 22). Retrieved January 18, 2005. www.cls.usask.ca/media/ opening_release.php.

Canadian Light Source Inc. 2004b. Synchrotron Facts. Retrieved January 18, 2005. www.cls.usask.ca/education/whatis.php.

Canadian Light Source Inc. 2004c. Science. Retrieved January 18, 2005. www.cls.usask.ca/science.

CBC News. 2004, October 21. Synchrotron FAQs: A Racetrack for Electrons. Retrieved January 18, 2005. www.cbc.ca/news/ background/synchrotron.

Western Economic Diversification Canada. 2004, November 23. Canadian Light Source (CLS) Synchrotron. Retrieved January 18 2005. www.wd.gc.ca/innovation/cdnlightsource/default_e.asp.

New website worth visiting www.fundingfacts.com

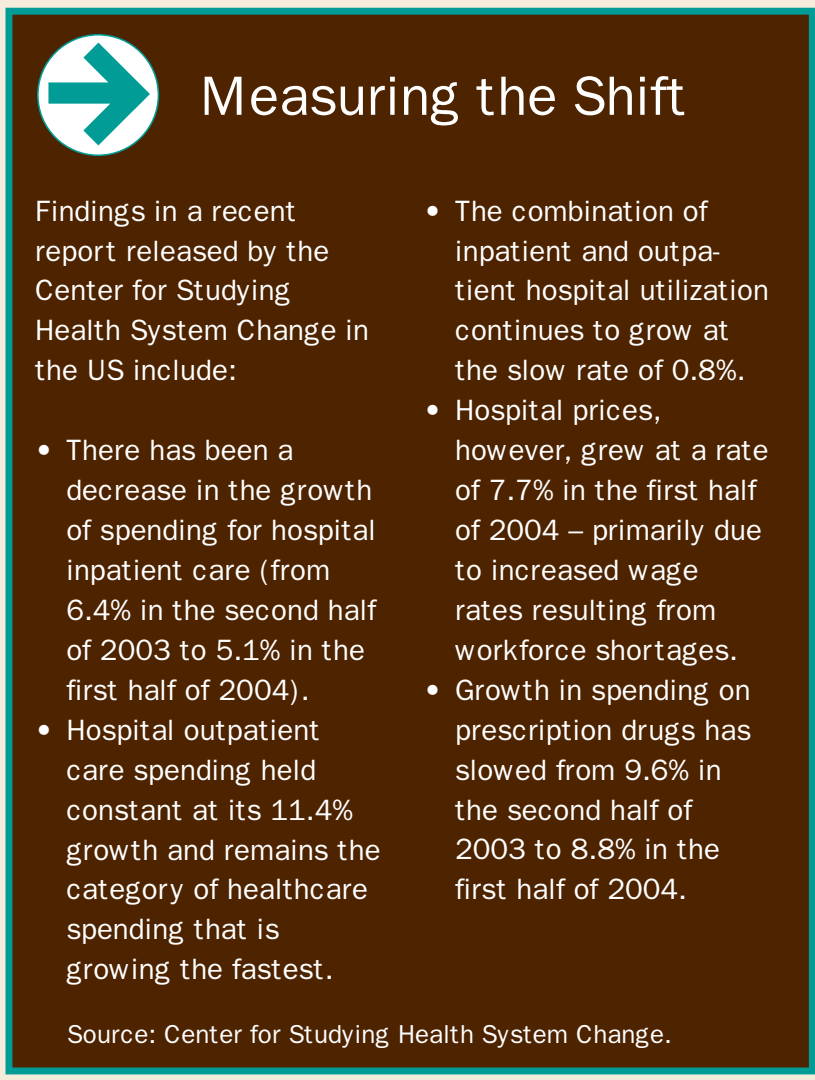

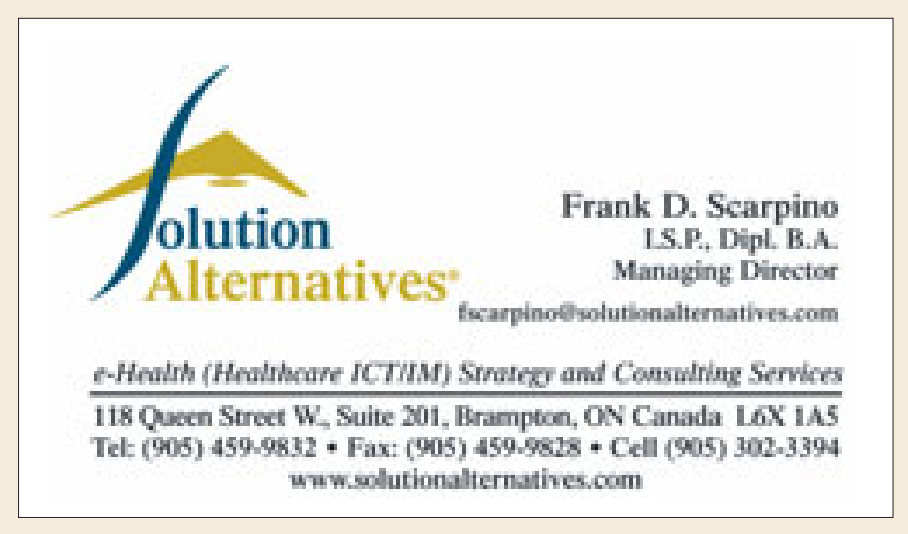

\section{Alliance Healthcare Group Inc.} Apothe Capes

Af ncti n I, t- ffe tive, $\mathrm{H}$ spit I Phar a y M n ge ent System.
Robyn Robinson, President $17 \mathrm{Hi}$ wa Avenue, London, ON N6C 2K4 Alliance Healthcare Group Inc.
Pho e: 519-439-6947 Toll Free: 1-888-673-6388 Fax: 519- 36-8485 Em il: $r @ h$ i .net www.ahginc.net 